VISCERAL SYPHILIS

SYPHILIS OF THE INTESTINE*

UDO J. WILE, A.B., M.D.

Professor of Dermatology and Syphilology, University of Michigan

ANN ARBOR, MICH.

\title{
INTRODUCTION
}

With the exception of syphilis of the rectum, syphilis of the intestine may be said to be a rare entity, at least from the clinical standpoint. The condition is recognized frequently, however, in syphilis of the new-born, and we are principally indebted to pathologic reports for literature on cases of true intestinal syphilis in the acquired form of the disease. The bedside recognition of the condition, which today perhaps is facilitated by the serologic examination, was a few years ago well-nigh impossible. A few cases recognized intra vitam are from time to time seen in surgical clinics in which the patients are operated on for various abdominal conditions simulated by syphilis. Thus, for example, intestinal obstruction, perforation, peritonitis, tuberculosis and carcinoma are conditions for which operation is occasionally resorted to, and in which syphilitic conditions of the bowel, both small and large, are occasionally encountered. Neumann, ${ }^{1}$ while stating that syphilis of the intestine is rare, mentions it as occurring somewhat more frequently than gastric syphilis; from my own study of the literature, I am convinced that it is no more frequent. Fraenkel, ${ }^{2}$ in an analysis of 19,000 postmortem examinations covering ten years, found only three cases of genuine intestinal syphilis. Oberndorfer, ${ }^{3}$ who has written an extensive monograph on the subject, has collected only twentyfour cases of authentic intestinal syphilis. In ninety cases of intestinal stenosis, however, nine are reported by Reach $^{4}$ as having been caused

* Studies and Contributions of the Department of Dermatology and Syphilology of the University of Michigan; service of Dr. Udo J. Wile.

1. Neumann: Nothnagel, Spez. Path. u. Therap., Hölder, Wien. 23:405, 1899.

2. Fraenkel: Ueber tertiare Darmsyphilis, München. med. Wchnschr. 48: 1262, 1901; Zur Lehrer von der Acquirirten Magendarmsyphilis, Virchow's Arch. 155:507, 1899. Friedreich: Zur Chirurgischen Pathologie von Netz. u. Mesenterium, Arch. f. klin. Chir. 61:998, 1900.

3. Oberndorfer: Ueber die viscerale Form der congenitalen Syphilis mit specieller Berücksichtigungen des Magen-Darmcanals, Virch. Arch. 159:179, 1900.

4. Reach: Cited by Goto, p. 208. 
by syphilis. Brunner ${ }^{5}$ believes with Neumann that syphilis of the intestine is more common than syphilis of the stomach, but he calls attention to the frequent association of both. During a period covering five years' observation of hospitalized syphilitic patients, I have seen three cases of gastric syphilis, but no cases of intestinal syphilis.

Of Oberndorfer's cases, sixteen were cases of syphilis of the small intestine; two cases occurred in the small and large intestine together, one occurred in the ileocecal region, and four in the large intestine. From this report, it will be seen that by far the largest number of cases of intestinal syphilis occur in the small intestine, and all authors agree that the jejunum is more frequently involved than any other portion of the small intestine. Horwitz ${ }^{6}$ has reported four cases of secondary sypihils associated with symptoms of chronic appendicitis, in which the symptoms disappeared entirely with mercurial treatment. In eleven cases collected by Rieder, ${ }^{7}$ seven occurred in the small intestine and three in the large; one occurred in the ileocecal valve. Syphilitic involvement of the cecum is described by Vantini. ${ }^{8}$ True syphilis of the appendix is described by Trinkler; ${ }^{9}$ syphilitic ulcers in the descending colon by Borchard, Rotter ${ }^{10}$ and Kummel. Gross ${ }^{12}$ found syphilis in the ascending and transverse colon. Most changes occur late in the disease and are therefore part of the so-called tertiary period. A secondary enteritis, however, is recognized.

\section{EARLY INVOLVEMENT}

Incidence.-In association with the early catarrhal gastritis, and sometimes independent of this, catarrhal enteritis associated with the exanthem of the secondary period is occasionally seen. It differs from simple catarrhal enteritis only in not yielding to ordinary measures. A positive diagnosis of early catarrhal enteritis is possible only when the eruption is coincident with the exanthem, when it resists ordinary therapeutic measures and disappears promptly on antisyphilitic treatment. Even then it may be asserted that the evidence of syphilitic

5. Brunner: Syphilis des Darms, Deutsch. Chir. 46E:333, 1907.

6. Horwitz: Four Cases of Secondary Syphilis Complicated with Chronic Appendicitis, Ann. Surg. 27:74, 1898.

7. Rieder, Zur Kenntnis der Specifisch Darmerkrankungen bei Acquirirte Syphilis, Hamburger Jahrbuch, No. 1.

8. Vantini: Cited by Brunner.

9. Trinkler: Mitt. a. d. Grenzgeb. d. Med. und Chir. 10:727; Chirurgische Kongress, 1904, p. 149.

10. Rotter: Cited by Brunner; Sigmoidio-Rectostomy, Langenbeck's Arch. 58: 334, 1899 .

11. Kummel: Cited by Brunner.

12. Gross: Cited by Brunner. 
involvement is merely presumptive. It is now, however, accepted that coincident with the exanthem on the skin a general visceral roseola occurs. A few cases are recorded in which postmortem examinations have been performed when the patient died of early syphilis, in which discrete patches of erythema and swelling of the lymphatic follicles have been noted in the intestinal mucosa. When one considers how frequently the spleen, liver and heart are affected with clinical symptoms, it is indeed not surprising that the intestinal mucosa should share in the general early involvement. It may properly be presumed, therefore, that early intestinal involvement is far more common from a pathologic standpoint than is manifested clinically. In a few cases early syphilitic catarrhal enteritis has become chronic.

Symptoms.-These do not differ from those of acute catarrhal enteritis from any other cause. More or less pain, diarrhea and occasionally tenesmus with the passage of a little blood are present. Associated may be gastralgia, definite gastric catarrh, vomiting and loss of appetite. From these symptoms, it is clear that a diagnosis without further evidence is presumptive only.

Course.-The cases usually run a mild course. They are readily amenable to treatment, and if left untreated, usually take the course of the "intestinal roseola" with a gradual spontaneous disappearance.

\section{LATE INVOLVEMENT}

Incidence.-Late involvement is more common than early involvement. Occasionally recognized at the bedside, it is more frequently found at necropsy or at operation.

Symptoms.-The symptoms of late syphilitic enteritis depend on the location and on the type of lesion. They therefore present the clinical picture of ulcer, of abdominal tumor, of stenosis and of intestinal obstruction. In nonulcerating gumma one may have definite narrowing of the lumen; occasionally symptoms of abdominal tumor simulating carcinoma appear. When such a gumma alcerates, the picture is one of an ulcerative enteritis with frequent diarrhea, with colicky pain and gradual emaciation. When such a lesion extends further and ulcerates into the peritoneum, the picture is in no way different from that of peritonitis. When there are numerous ulcers, such as have frequently been described, particularly in the jejunum, the clinical picture is identical with that of tuberculosis. There may be more or less fever; there is diarrhea with occasional periods of constipation; through partial healing there may be cicatrization and narrowing with symptoms of partial obstruction. When the ulcers have healed, whether they are superficial or deep gummas, the picture is identical with that of ileus. Cases simulating tuberculosis are recorded 
by Guttmann, ${ }^{13}$ Hueter, ${ }^{14}$ and Blackmore. ${ }^{15}$ The location of syphilis of the intestine near the ileocecal valve or the appendix may simulate appendicular colic.

The characteristic symptoms-pain, diarrhea, blood and pus, together with complications such as stenosis and ileus-make the symptoms identical with those of chronic ulcerative enteritis. Jaundice is noted as occurring by an extension of the process into the common bile duct (Oberndorfer ${ }^{3}$ ). An interesting case is reported by Fischer ${ }^{\mathbf{1 6}}$ in which a diagnosis of sarcoma of the ileum was made owing to an enormous tumor of the lower quadrant. Operation was considered impossible, but antisyphilitic treatment brought about complete recovery. In one of Fraenkel's cases, in which general peritonitis had occurred from perforation, ulcers were found in both the stomach and intestine. Cases in which recovery followed operation are also reported by Elder ${ }^{17}$ and Rosenfeld. ${ }^{1 / 5}$ In Solms' ${ }^{19}$ case, in which the lesion was located in the splenic flexure of the colon, the picture was that of intestinal perforation, peritonitis and death. In Rosenfeld's case, a diagnosis was made intra vitam of syphilitic stenosis of the small intestine. This was substantiated at operation, and the patient made an excellent recovery. Cases simulating carcinoma are reported by Fraenkel and Goto. ${ }^{20}$

As a part of late syphilis, but in no way diagnostic of it, must be mentioned amyloid disease of the intestine. This is relatively uncommon. The diagnosis is invariably made postmortem; the symptoms are those of chronic ulcerative enteritis, or indeed, of amyloid disease which may be found due to inveterate syphilis with no symptoms referable to the gastro-intestinal tract.

Course.-In well developed cases, the course usually leads to a fatal outcome, generally caused by failure of diagnosis and from such complications as ileus and perforation. As a rule, the disease may drag

13. Guttmann: Multiple Dunndarmgeschwure hochstwahrscheinlich Syphi1itischer Natur, Ztschr. f. klin. Med. 50:404, 1903.

14. Hueter: Ueber Darmlues, München. med. Wchnschr. 53:284, 1906.

15. Blackmore, A.: A Case of Syphilitic Ulceration of the intestine, Lancet 2:615, 1885 .

16. Fischer: Syphilis of the Stomach and Intestines, with Report of Cases, Monograph read at meeting of the Medical Association of Georgia, 1915.

17. Elder: Acute Intestinal Obstruction Caused by Syphilitic Ulceration in the Ileum. Brit. M. J. 1:1068, 1904.

18. Rosenfeld: Die Syphilitische Dunndarmstenose, Berl. klin. Wchnschr. 39: No. 307, 1902.

19. Solms: Kasuistische Beitrage zur Pathologie der Magen und Darmkrankheiten, Arch. f. Verdauunzskr. 17:174, 1911.

20. Goto: Beiträge zur Erworbenen Syphilis der Ileocaecalgegend, Arch. f. Deutsch. Chir. 97:207, 1912. 
on for many years with vague undiagnosed intestinal complaint, as in cases reported by Riedel, ${ }^{21}$ and this symptom of long chronicity is pointed to as of some value by Brunner. A few cases, however, are abrupt, complications and death occurring in a short time after the onset of the first symptoms.

Diagnosis.-Depending on the stage of the process and the location of the lesions, the cases of intestinal syphilis must be differentiated from carcinoma, tuberculous enteritis, intestinal obstruction and from adhesive peritonitis with narrowing of the lumen. With our modern laboratory tests and the careful scrutiny of all patients before operation, cases of intestinal syphilis should be somewhat more easily recognizable. The positive Wasermann test, in association with symptoms such as have been described, may be regarded as presumptive evidence at least of syphilis as the cause of the intestinal involvement. In any event, such patients should be given the benefit of vigorous antisyphilitic treatment before other measures are decided on. Without the laboratory aid, the differential diagnosis at the bedside is acknowledged to be difficult, if not impossible. The cases are far too few for any one clinician to have had extensive clinical experience. In this connection it must also be remembered that intestinal syphilis may occur with a negative Wassermann reaction, such as in Fischer's case; and that the positive Wassermann reaction may be the result of syphilis incident to another intestinal condition.

Prognosis. - The progonosis is bad, perhaps largely due to the failure of early diagnosis. There are probably many cases in which intestinal lesions occur in which spontaneous healing with more or less narrowing of the lumen of the intestine occurs, and in which the patients spontaneously recover. Cases, however, with distinct symptoms of ulcerative enteritis usually drag on undiagnosed for so long that serious complications make the prognosis unfavorable.

Treatnent.-The treatment is that of general syphilis. ${ }^{22}$

21. Riedel: Ileus un Folge von etwas aufsergewöhnlichen Strangbildungen, Verwachsungen und Achsendrehungen, sowie von Darmsyphilis, Mitt. a. d. Grenzgeb. d. Med. u. Chir. 2:483, 1897.

22. In addition to the references already given, the following may be of interest:

Friedreich: Zur Chirurgischen Pathologie von Netz. u. Mesenterium, Langenbeck's Arch. 61:998, 1900.

Fournier and Lereboullet: Diarrhées Syphilitiques Tertiaire, Gaz. hebd. de méd., N. S. 5:637, 1900.

Ringel: Syphilitische Darmstenose, Deutsch. med. Wchnschr. 25:11, 1899.

Weiss: Die Syph. Erkrankungen des Darms., Centralb1. f. d. Grenzgeb. d. Med. u. Chir. 5:577 and 625, 1902. 